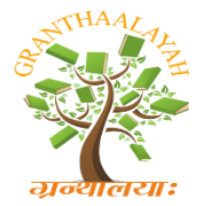

\author{
INTERNATIONAL JOURNAL OF RESEARCH - \\ GRANTHAALAYAH \\ A knowledge Repository
}

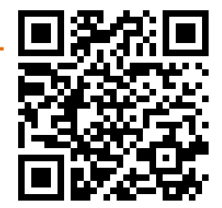

Science

\title{
DEVELOPMENT OF PRODUCTION RATE DECLINE-BASED SOFTWARE FOR RESERVOIR PERFORMANCE PREDICTION
}

\author{
Innocent O. Oboh ${ }^{1}$, Anietie N. Okon ${ }^{2}$, Hocaha F. Enyi ${ }^{3}$ \\ ${ }^{1,2,3}$ Department of Chemical and Petroleum Engineering, University of Uyo, Nigeria
}

\begin{abstract}
The need for predicting the performance of hydrocarbon reservoirs has led to the development of a number of software in the Petroleum industry. Lots of these available software handled virtually all tasks in reservoir engineering ranging from estimation, forecasting, history matching, among others. That notwithstanding, improvements on these software are still been made and newer versions are released to meet users' requirements. In this work, software "ULTIMATE" was developed based on production rate decline analysis to predict reservoir performance. Also, the developed software "ULTIMATE" handles Inflow Performance Relationship (IPR) prediction. The developed software prediction based on data obtained from two wells were compared with another software MBAL 10.5 developed by petroleum Experts Limited. The results of the comparison indicated that the developed ULTIMATE software predictions were very close to the MBAL 10.5 predictions. Additionally, the incorporated parallel algorithm in the ULTIMATE software enables it to analyze more wells and with more speed than the other software (MBAL 10.5). Therefore, the developed ULTIMATE software can be use as quick tool for predicting reservoir performance based on production rate decline analysis. Furthermore, the developed software would be improved to handle reservoir performance predictions based on Materials Balance Equation (MBE), and other production rate-related predictions like coning parameters estimation.
\end{abstract}

Keywords: Reservoir Performance Prediction; Decline Curve Analysis; Visual Basic; Software.

Cite This Article: Innocent O. Oboh, Anietie N. Okon, and Hocaha F. Enyi. (2019). "DEVELOPMENT OF PRODUCTION RATE DECLINE-BASED SOFTWARE FOR RESERVOIR PERFORMANCE PREDICTION." International Journal of Research - Granthaalayah, 7(6), 49-55. https://doi.org/10.29121/granthaalayah.v7.i6.2019.749.

\section{Introduction}

The uses of software programs in the oil and gas industry have grown extensively over the last few decades, as they are used in modelling and simulation of reservoir performances. Interestingly, several software programs are available in the industry, some of which include: ECLIPSE, PETREL, FEKETE, SENSOR, Petroleum Experts that consists of GAP, MBAL, PROSPER, REVEAL, RESOLVE, PVTi and PVTP, as well as other host of software packages. These 
software programs are carefully designed to provide a wide variety of reservoir modelling and simulation study functions and operations. According to Dixit (2005) software is a sequence of instructions (i.e., codes) given to a computer to perform a particular task. The foundation of the codes which are written across different programming language platforms are based on published and widely acceptable correlations from field research. Also, assumptions from these correlations are carefully integrated into the fabric of these software codes. So far, some of these languages which can be used for the design of these software programs include Visual Basic.NET, C++, Python, C\#, Java and Oracle (Microsoft Visual Studio, (online)). Although the flexibility of these languages varies, skillful use of any or a combination these languages can yield flexible user friendly application software. However, the robustness, flexibility and versatility of software have an intrinsic value tied to the stock of codes that are at work in the background (Enyi, 2015). Currently, Visual Basic.NET has become the favourite program for developers because of its simplicity and presence of Common Language Runtime (CLR); to manage the execution of .NET programs (Roman et al., 2001). Also, Parihar (2002) maintained that the CLR provide a number of benefits to the developer, which includes: exception handling, security, debugging, and versioning; as these benefits are available to any language built for the CLR. This implies that the CLR can host several languages and offer a common set of tools across these languages. Thus, Microsoft has made VB (Visual Basic), C++ and C\# "premier" languages for the CLR, which means that these languages fully support the CLR. The use of these software packages have helped professionals in the Exploration and Production (E\&P) field to gain insight into the behaviour of the reservoir and its occupying fluid, the influence of the reservoirs changing parameters like reservoir pressure on production rates, predictions of flow rates and recoveries, understanding flow regimes and pressure changes, performance relationships, etc. Also, they have provided a platform for virtual testing of different equipment and its effect on production of the desired reservoir fluid like modelling a gas-lifted well (Enyi, 2015).

There are several approaches in the literature which are used to predict the reservoir future production performance as a function of time. These include: material balance equation (MBE), production decline analysis and reservoir simulation model. Okon et al. (2017b) maintained that one of the approaches of estimating the reservoir recoverable reserves is the reservoir performance analysis using production rate decline analysis. Hook (2009) added that decline curve analysis (DCA) is the frequently used approach for recoverable reserves estimation as it is a function of rate of decline of petroleum extraction over a period of time. Therefore, this approach is based on the assumptions that the trend of production history of oil and/or gas reservoir(s) and factors causing the historical decline remain unchanged during the forecast period (Okon et al., 2017a). Therefore, this paper aims at developing a software that will be used for reservoir performance prediction based on decline curve models.

\subsection{Production Rate Decline Model}

The first production rate decline model was proposed by Arps (1945). This model further resulted in three (3) types of equations (as presented in Table 1) depending on its decline exponent. However, a great number of studies on production decline analysis are still based on this empirical model by Arp (1945) (Rahuma et al., 2013). As a result, Reese et al. (2007) and Johnson et al. (2009) presented reciprocal and quadratic models respectively, for production rate decline analysis. The reciprocal model assumed that flowing well bottom-hole pressure was approximately 
constant and was used to estimate hydrocarbon reserves using only rate-time production data. This model requires a plot of the reciprocal of production rate $\left(q^{-1}\right)$ against the cumulative production to production rate ratio $\left(N_{p} / q\right)$ as presented in Table 1. Additionally, the quadratic model as developed by Johnson et al. (2009) was based on the Semi-analytical formulation by Blasingame and Rushing (2005) and Empirical formulation by Ilk et al. (2008). In essence, decline curves of various forms as mentioned can be used to create significant outlooks for hydrocarbon production of a single well or an entire field.

Table 1: Production Rate Decline Models

\begin{tabular}{|l|l|l|l|}
\hline S/N & Author(s) & Models & Production Rate (qt) \\
\hline 1. & Arps (1945) & Exponential & $q_{t}=q_{i} e^{-D_{i} t}$ \\
\cline { 4 - 4 } & & Harmonic & $q_{t}=\frac{q_{i}}{\left[1+D_{i} t\right]}$ \\
\cline { 1 - 2 } 3. & & Hyperbolic & $q_{t}=\frac{q_{i}}{\left[1+D_{i} b t\right]^{1 / b}}$ \\
\hline 4. & Reese et al. (2007) & Reciprocal & $\frac{1}{q_{t}}=\frac{1}{q_{i}}+\frac{D_{i}}{q_{i}}\left(\frac{N_{p}}{q_{t}}\right)$ \\
\hline 5. & Johnson et al. (2009) & Quadratic & $q_{t}=q_{i}-D_{i}\left(N_{p}\right)+\frac{D_{i}^{2}}{q_{i}}\left(N_{p}\right)^{2}$ \\
\hline
\end{tabular}

Source: Okon et al. (2017b)

where:

$q_{t}=$ Production Rate at time $t$, Stb/day

$q_{i}=$ Initial Production Rate, Stb/day

$t=$ time, Days

$D_{i}=$ Decline Constant, Day ${ }^{-1}$

$b=$ Decline Exponent

$N_{p}=$ Cumulative Oil Production, Stb

\section{Software Development}

The developed ULTIMATE software is designed to predict reservoir performance based on production rate decline analysis. The software is developed to run on Windows Operating Systems with the system specifications as presented in Table 2. In addition, the generalized design and flowchart of the developed ULTMATE software are presented in Figures 1 and 2. Also, the parameters dashboard that contains all the basic data that must be entered to complete the reservoir performance prediction is depicted in Figure 3. The additional feature of this developed ULTIMATE software is that it handles Inflow Performance Relationship (IPR) prediction of the reservoir as well. In other words, the developed software has both production rate decline and inflow performance analyzers. 
Table 2: Recommended System Requirements

\begin{tabular}{|l|l|}
\hline Operating System & Windows OS \\
\hline RAM & 4GB \\
\hline Bit size & 64bit or 34 bit \\
\hline Hard Disk & $500 \mathrm{~GB}$ \\
\hline Processor & At least $1.9 \mathrm{GHz}$ \\
\hline .NET framework & .NET 4.5 or higher \\
\hline Windows & $7,8,8.1$ and 10 \\
\hline
\end{tabular}

-Well Data

-Published Correlation and Relations

\section{Data Collation}

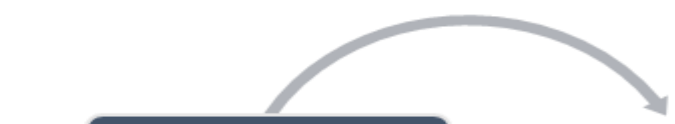

\section{Programming}

-Algorithm Creation/Interface Design

-Coding / Debugging
- Result Validation

- Comparative error Correction.

Verification

Figure 1: Generalized Design for ULTIMATE Software

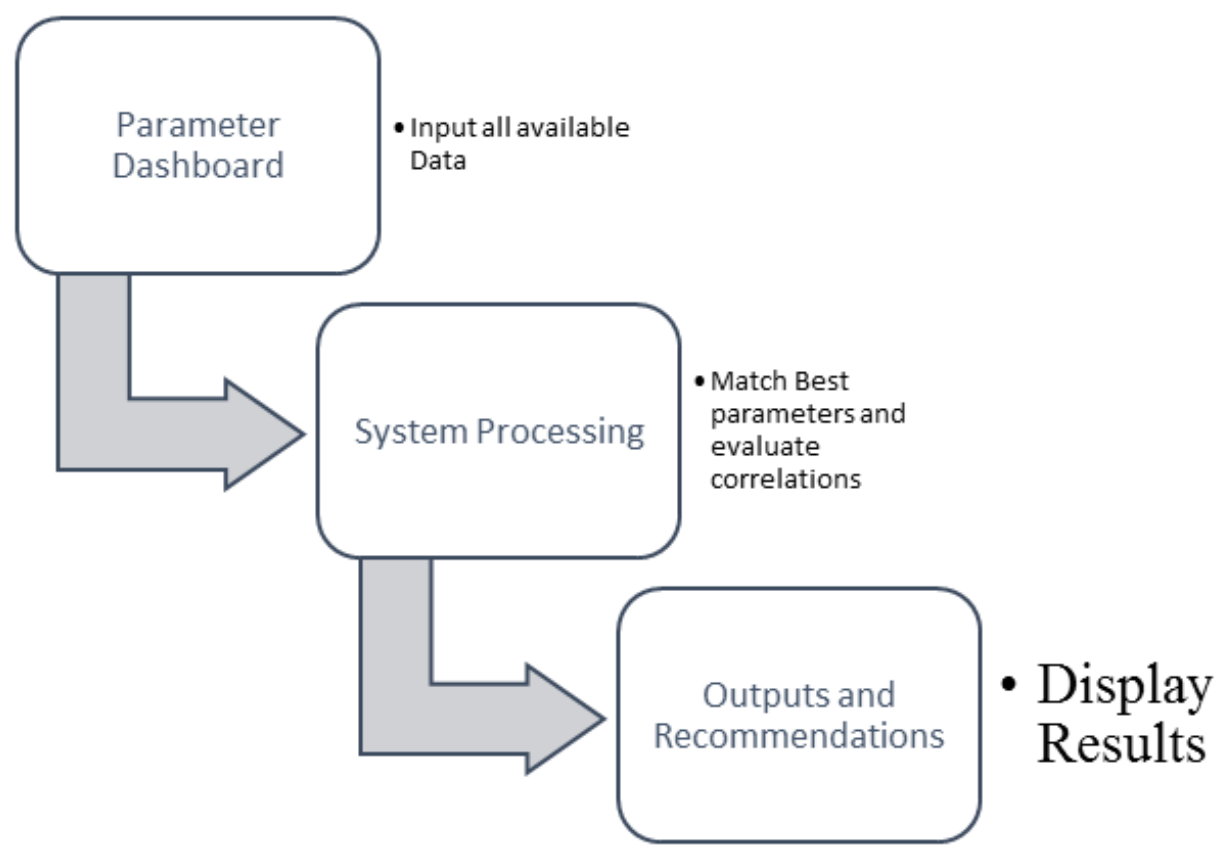

Figure 2: Flowchart of ULTIMATE Software 


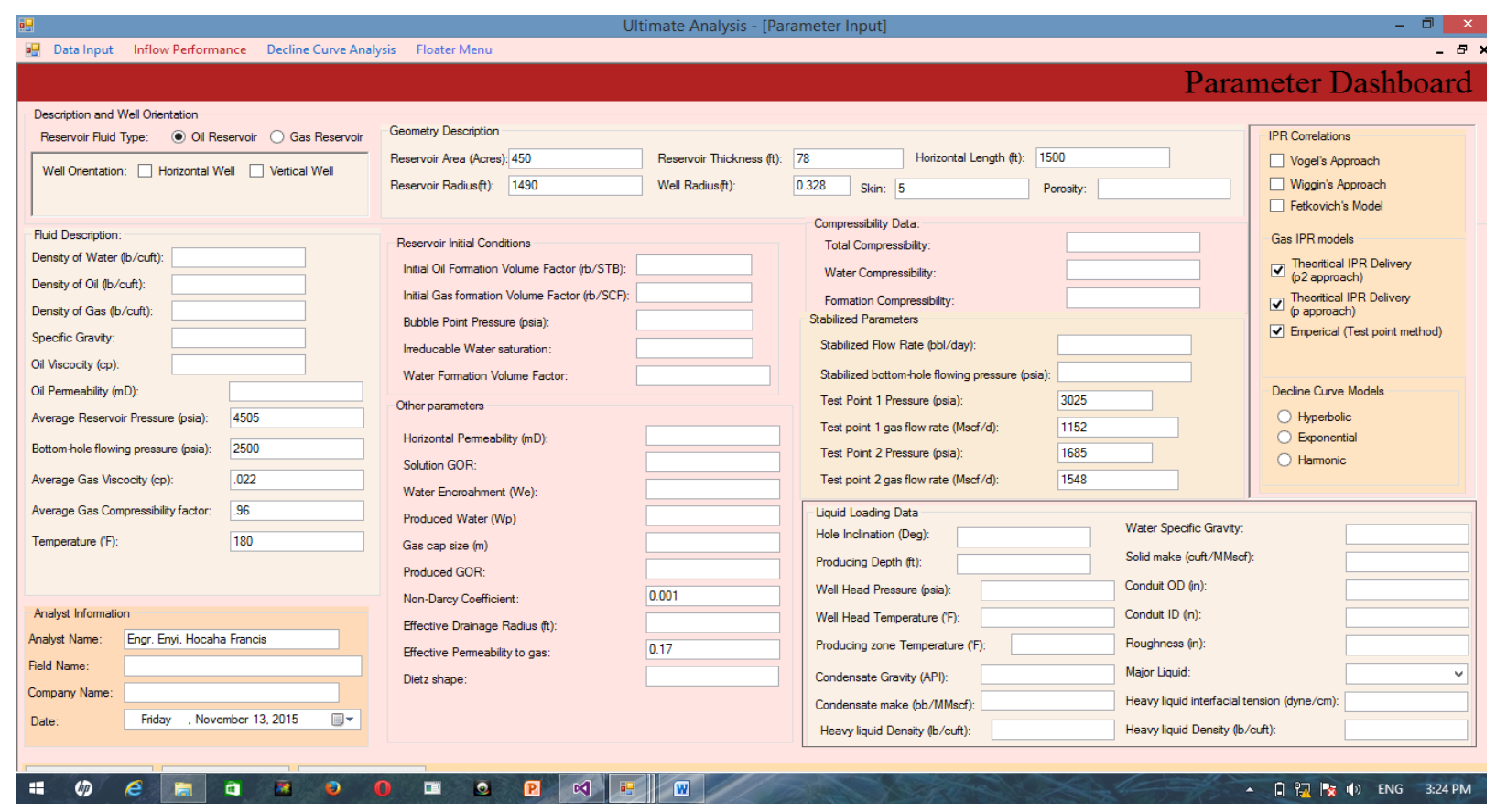

Figure 3: Parameters Dashboard

\section{Software Prediction and Evaluation}

The developed ULTIMATE software performance was evaluated with data obtained from two wells. The obtained data were initial production rates $\left(\mathrm{q}_{\mathrm{i}}\right)$ and the production rate decline constants $\left(D_{i}\right)$ of the wells; as shown in Table 3. The results of the evaluation with the developed ULTIMATE software are presented in Figures 4 and 5. In addition, the developed ULTIMATE software predicted the inflow performance curve of the wells; as observed in Figure 6. Thereafter, the performance of the developed ULTIMATE software was compared with MBAL 10.5 software developed by Petroleum Experts Limited. Interestingly, the developed ULTIMATE software handled more than one well at a time, unlike the MBAL 10.5 software that handles just one well at a time. Thus, the developed ULTIMATE software's parallel algorithm makes it to simultaneously analyze up to 20 wells at the same time; a feature that is of added advantage over the MBAL 10.5 software. Furthermore, MBAL 10.5 software completed decline curve analysis simulation for a single well in about five minutes while the developed ULTIMATE software would complete for five wells for the same period of five minutes. The decline analysis prediction of the both software (i.e. the developed ULTIMATE and MBAL 10.5) are presented in Figure 7.

Table 3: Obtained Well Production Parameters

\begin{tabular}{|l|l|l|}
\hline Wells & Initial Production Rate $\left(\mathbf{q}_{\mathbf{i}}\right)$ & Rate Decline Constant $\left(\mathbf{D}_{\mathbf{i}}\right)$ \\
\hline Well 1 & $2000 \mathrm{STB} / \mathrm{D}$ & $2.0 /$ year \\
\hline Well 2 & $2500 \mathrm{STB} / \mathrm{D}$ & $2.5 /$ year \\
\hline
\end{tabular}

\subsection{Prediction Results Discussion}

As earlier alluded, the developed ULTIMATE software predictions for the two wells were validated with MBAL 10.5 software predictions. This validation result is presented in Figure 7, as 
observed, there is a very close match between the both software's predictions. This implies that the developed ULTIMATE software has close prediction potentials when compared to its MBAL 10.5 counterparts. In other words, the developed ULTIMATE software can perform reservoir performance prediction using decline curve analysis just like other available software in the Petroleum industry.

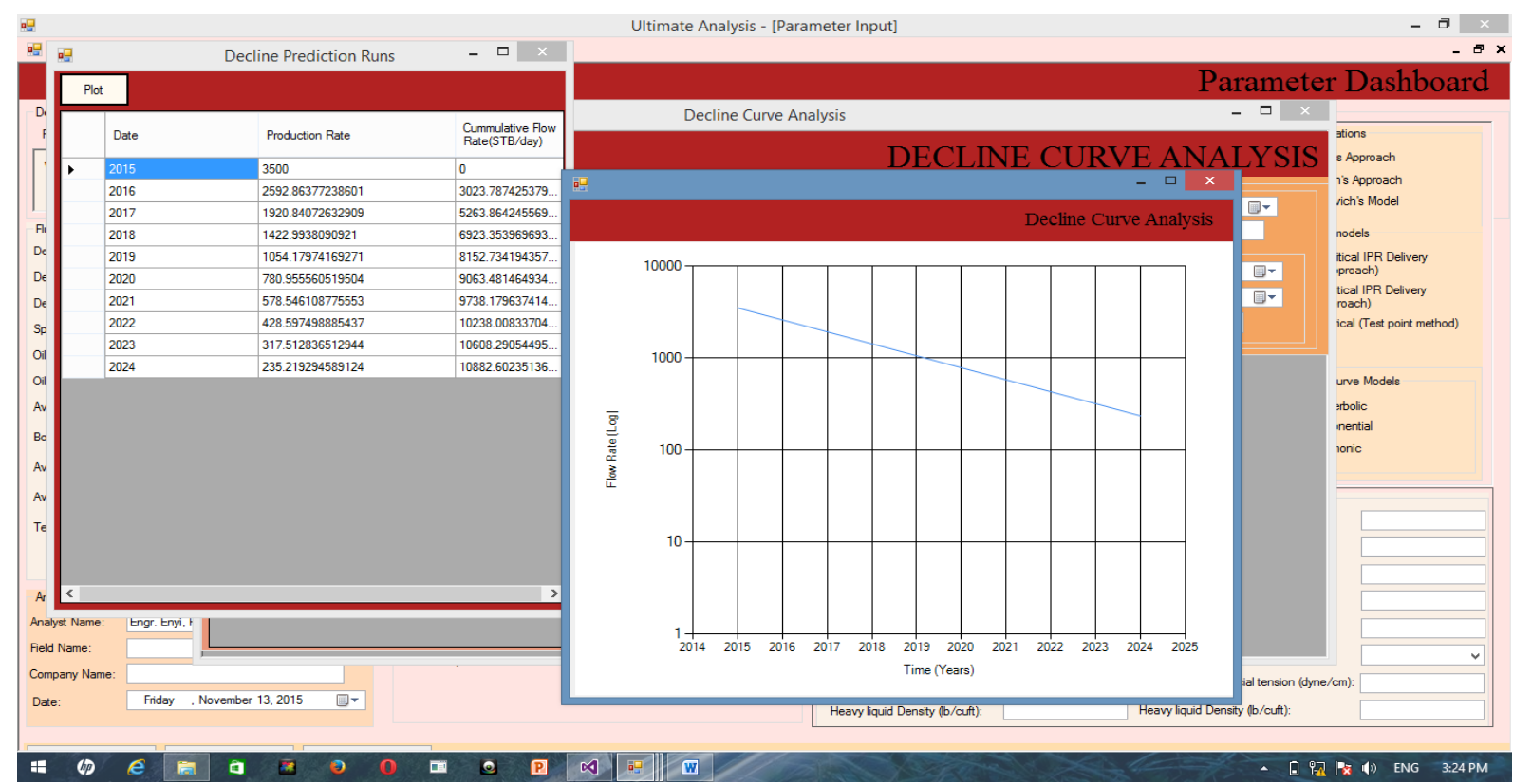

Figure 4: Developed Software Decline Curve Analyzer Window with Decline Plot

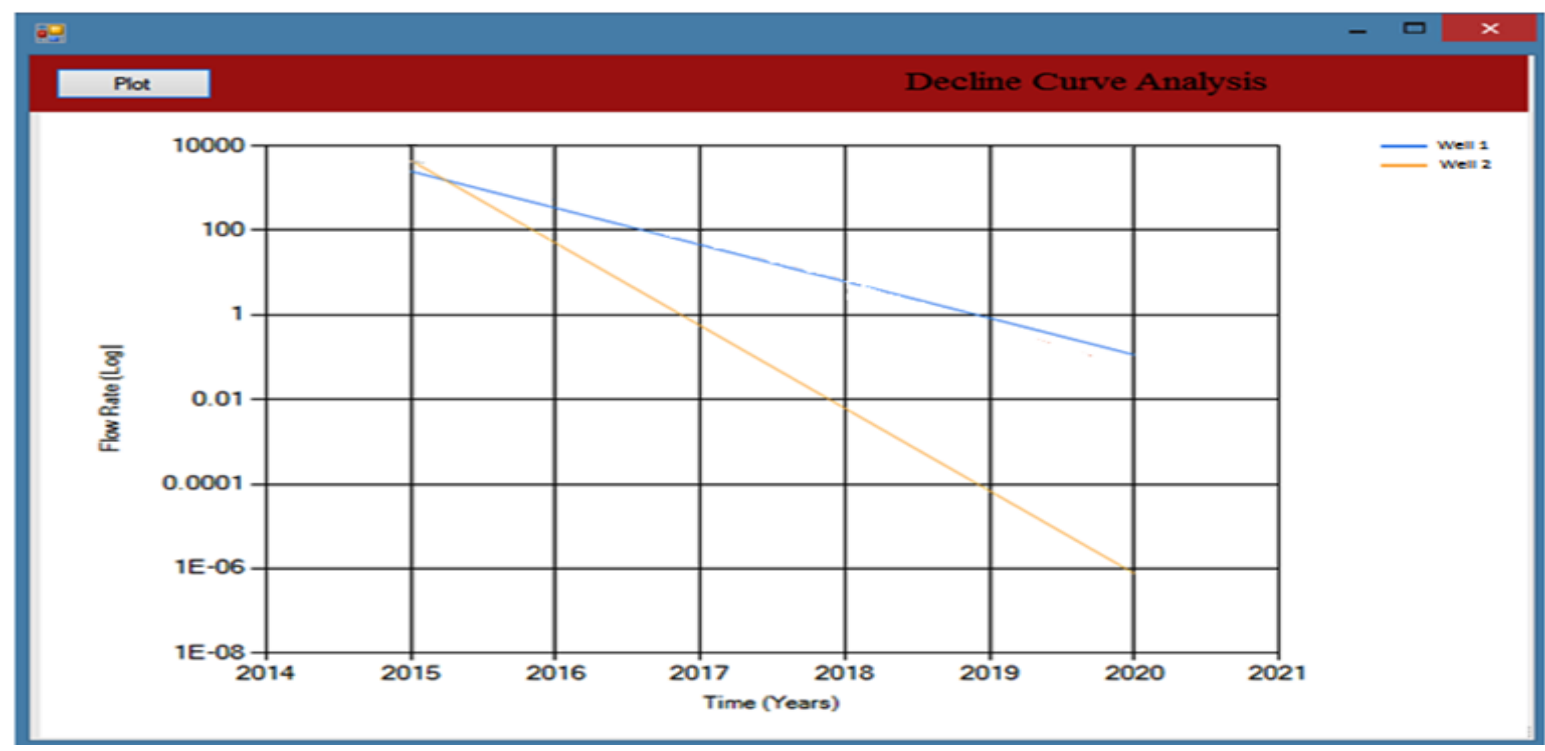

Figure 5: Obtained Decline Plot with the Developed ULTIMATE Software

\section{Conclusion}

The developed software has demonstrated strong rate decline analysis when compared with other software. The incorporated parallel algorithm in the developed software is a great advantage to be 
exploited, as it enables the software to analyze more wells and with more speed than other software. Thus, it is recommended that the ULTIMATE software should be further improved upon to perform reservoir performance prediction based on Material Balance Equation (MBE) approach as well. Also, coning phenomenon estimation should be incorporated in the developed software to widen its application in the Petroleum industry.

\section{References}

[1] Dixit, J. B. (2005). Fundamental of Computers and Programming in C. Laxmi Publications (P) Ltd, New Delhi, India.

[2] Microsoft Visual Studio (online). https://en.wikipedia.org/wiki/Microsoft_Visual_Studio. Accessed: $5^{\text {th }}$ August, 2015.

[3] Enyi, H. F. (2015). Development of I-RESWELL Software for Reservoir Modelling and Performance Prediction. Unpublished B.Eng. Project submitted to the Department of Chemical and Petroleum Engineering, Faculty of Engineering, University of Uyo, Nigeria.

[4] Roman, S., Petrusha, R. and Lomax, P. (2001). VB.NET Language in a Nutshell. Sebastobol, California: O'Reilly Publishers.

[5] Parihar, M. (2002). ASP.NET Bible. Wrox Press Publishing Ltd. London.

[6] Okon, A. N., Edem, U. U. and Olagunju. D. T. (2017b). Production Rate Decline-Based Models for Oil Reservoir Performance Prediction in Niger Delta. International Journal of Engineering Research and Technology, Vol. 6, No. 7, pp. 454-465.

[7] Okon, A. N., Olagunju. D. T. and Akpabio, J. U. (2017a). Rate Decline-Based Models for Gas Reservoir Performance Prediction in Niger Delta Region. British Journal of Applied Science and Technology, Vol. 19, No. 6, pp. 1-14.

[8] Hook, M. (2009). Depletion and Decline Curve Analysis in Crude Oil Production. Unpublished M.Sc. Thesis submitted to the Department of Physics and Astronomy, Uppsala University.

[9] Arps, J. J. (1945). Analysis of Decline Curves. Transactions of the American Institute of Mining, Metallurgical and Petroleum Engineers. Vol. 160, pp. 228-247.

[10] Rahuma, K. M., Mohamed, H., Hissein, N. and Giuma, S. (2013). Prediction of Reservoir Performance Applying Decline Curve Analysis. International Journal of Chemical Engineering and Applications, Vol. 4, No. 2, pp. 74-77.

[11] Reese, P. D., Ilk, D. and Blasingame, T. A. (2007). Estimation of Reserves using the Reciprocal Rate Method. Paper presented at the Society of Petroleum Engineers, Rocky Mountain Oil and Gas Technology Symposium held in Denver, Colorado, U.S.A., 16-18 April.

[12] Johnson, N. L., Currie, S. M., Ilk, S. M. and Blasingame, T. A. (2009). A Simple Methodology for Direct Estimation of Gas-in-place and Reserves Using Rate-Time Data. Paper presented at the Society of Petroleum Engineers, Rocky Mountain Petroleum Technology Conference held in Denver, Colorado, USA, 14-16 April.

[13] Blasingame, T. A. and Rushing, J. A. (2005). A Production-Based Method for Direct Estimation of Gas-in-place and Reserves. Paper presented at the Society of Petroleum Engineers, Eastern Regional Meeting, Morgantown, West Virginia. 14-16 September.

[14] Ilk, D., Perego, A. D., Rushing, J. A. and Blasingame, T. A. (2008). Exponential vs. Hyperbolic Decline in Tight Gas Sands - Understanding the Origin and Implications for Reserve Estimates using Arps' Decline Curves. Paper presented at the SPE Annual Technical Conference and Exhibition, Denver, Colorado, 21-24 September.

[15] MBAL 10.5 (2010). Reservoir Engineering Toolkit. Petroleum Experts Limited.

*Corresponding author.

E-mail address: innocentoboh@ uniuyo.edu.ng 